\title{
Comparison of Mean Glasgow Outcome Score in Patients with Traumatic Brain Injury after Magnesium Sulphate Therapy and Placebo. A Prospective Study of Shaikh Zayed Hospital Lahore
}

\author{
KAZIM ALI ${ }^{1}$, MUHAMMAD IRFAN ${ }^{3}$, RABIA ABBAS ${ }^{3}$ \\ MUHAMMAD AFAQ SARWAR ${ }^{1}$, KAMRAN HUSSAIN ${ }^{1}$ \\ Departments of ${ }^{1,3}$ Neurosurgery, ${ }^{2}$ Hematology, Shaikh Zayed Hospital \\ ${ }^{3}$ Punjab Institute of Neurosciences (PINS), Lahore - Pakistan
}

DOI 10.36552/pjns.v24i2.451

\begin{abstract}
Objective: Traumatic brain injury (TBI) is the number one cause of death under 44 years of age; in spite of this fact, there is no standard available pharmacological agent for the treatment of brain injury. It has a poor prognosis when misdiagnosed or a delayed treatment can lead to significant morbidity. We evaluated the effectiveness of magnesium sulphate treatment for the management and outcome of TBI.
\end{abstract}

Material and Methods: The prospective cases $(n=112)$ of TBI were included from Department of Neurosurgery, Shaikh Zayed Hospital, Lahore. Patients were split into two groups. Magnesium sulphate treatment group $(n=$ 56) and placebo group $(n=56)$. Detailed history of patients was taken along with comprehensive examinations with CT scans.56 TBI patients were given standard treatment plus magnesium sulphate and remaining 56 patients received just standard treatment.

Results: Mean age of the magnesium supplement therapy group was $36.83 \pm 13.45$ years while in the placebo group was $33.64 \pm 12.88$ years). Majority 28 (67.9\%) were male in the magnesium sulphate group while 37 $(66.1 \%)$ were in the placebo group. Mean duration passed between hospital presentation and traumatic brain injury was $4.98 \pm 2.32$ hours in the magnesium sulphate group while it was $5.05 \pm 2.48$ in the placebo group. Mean Glasgow outcome score was $3.57 \pm 1.33$ in the magnesium sulphate group while $2.78 \pm 1.23$ in the placebo group and this difference was statistically significant.

Conclusion: There is significant improvement in GOS after magnesium sulphate therapy in patients with traumatic brain injury versus placebo group as noted in the results.

Keywords: Glasgow Outcome Score, Traumatic Brain Injury.

\section{INTRODUCTION}

An external force when comes in contact to the head or body causes central nervous system dysfunction and damage that results in injury to the brain (TBI); there are several scales available to quantify the TBI. The scales which are routinely used for assessment include the Glasgow Coma Scale (GCS) score and the time period of loss of consciousness or post traumatic amnesia. ${ }^{1}$

Severe traumatic brain injury (TBI) is a leading cause of morbidity and mortality worldwide. ${ }^{2}$ TBI leads to amnesia, loss of consciousness, paralysis, and even death; the average age of patients with brain injury ranged from 27 to 59.67 years. ${ }^{3}$ The overall mild: moderate: severe ratio was 55: 27.7: 17.3 based on Glasgow Coma Scale (GCS). Asia ranked highest in percentage of Motor vehicle related TBIs. The percentage of fall and work related TBIs was highest. ${ }^{3}$

The number one cause of death under 44 years of age is TBI; in spite of this fact, there is no standard 
available pharmacological agent for the treatment of brain injury. Medical management of patients with TBI is part of pre hospital triage. The aim of the treatment is to protect the brain from damage that occurs later (secondary brain insult). ${ }^{4}$

In the early phase of TBI, the excitotoxicity leads to necrosis, apoptosis, necroptosis, autophagy, or pyroptosis. Excitotoxic events and their relationship to neuronal death pathways in TBI has been extensively researched. Even then, after 45 years of research most therapies against excitotoxic events have not been effective clinically. There are very few options available to improve clinical outcomes after traumatic brain injury in spite of many years of research. ${ }^{5}$

With reference to various researches, magnesium sulfate administered after a brain injury (diffuse axonal injury) has proved to be a useful protective agent for central nervous system. In a research significant improvement was noticed in Glasgow outcome scale after acute magnesium sulphate therapy in patients with TBI at 3 months. ${ }^{6}$

In another study, patients admitted within one hour after severe brain injury who fulfill the inclusion standards were selected with random sampling. They were divided into two groups.

\section{Dose}

Patients were given a bolus dose of fifty $\mathrm{mg} / \mathrm{kg}$ magnesium sulfate and then after every six hours, fifty $\mathrm{mg} / \mathrm{kg}$ of $\mathrm{MgSO}_{4}$ was given up to twenty four hours after the brain injury.

The outcome was assessed by Glasgow Coma Scale (GCS) score, mortality, and motor function scores which were checked up to two months after TBI. There was statistically significant improvement of GCS score at two months after trauma in patients who were given Magnesium Sulphate. ${ }^{7}$ There was also improvement in the Motor function scores of patients who were given MgSO4. Although, this was not statistically significant ( $\mathrm{P}$ equal to 0.51). Several studies have shown around $50 \%$ fall in brain free magnesium levels within hours after TBI. Clinical outcome is significantly improved when magnesium levels are restored back to baseline with various pharmacological approaches available. ${ }^{7}$

In a study done by Ling Zhao and others, there was higher GCS and significant lower GOS in MST (magnesium sulphate therapy) group as compared to placebo group. GCS scores on $3^{\text {rd }}$ day in the Magnesium sulphate therapy group $(7.39 \pm 2.07$ with $\mathrm{MgSO}_{4}$ and $6.23 \pm 2.29$ without $\mathrm{MgSO}_{4}$ ). The mean
Glasgow outcome score was significantly lower in the $\mathrm{MgSO}_{4}$ group at discharge and one month post discharge. ${ }^{8}$

A current meta-analysis of existing randomized controlled trials suggested that magnesium sulfate therapy is a useful agent in improving the Glasgow Outcome Scale and Glasgow Coma Scale scores, this is an encouraging data for TBI treatment. ${ }^{9-10-11}$

Magnesium has neuro protective role through various mechanisms, including NMDA receptor blockade, vascular smooth muscle relaxation, inhibition of excitatory neurotransmitter release and blockade of calcium channels. ${ }^{12-13-14}$

The aim of the study was to determine mean GCS and Glasgow outcome score in patients with traumatic brain injury after magnesium sulphate therapy. We designed this study to test the notion that treating a traumatic brain injury in patients with magnesium would improve outcome in short and long term after trauma. It will be a useful addition to the community knowledge. Data can be used by the care providers in investigating the problem and its management.

\section{MATERIAL AND METHODS}

\section{Study Setting}

The study design was quasi experimental. This study was conducted in the Department of Neurosurgery at Sheikh Zayed Hospital, Lahore from May 2018 to July 2019. We enrolled 112 patients who were presented with traumatic brain injury (TBI). They were divided into two groups; 56 patients in Magnesium sulphate group and 56 patients in the placebo group. Informed consents were taken from all patients or their attendants conformed to institutional ethical standards.

\section{Sampling Technique}

Patients were selected on the basis of non-probability consecutive sampling. Patients background information and clinical presentations were recorded. Patients were evaluated consisting of a detailed history, physical examination (history of LOC, ENT bleed, fits, vomiting, antegrade and retrograde amnesia).

\section{Inclusion Criteria}

We included patients of both genders with traumatic brain injury with age between $18-70$ years who gave consent. 


\section{Exclusion Criteria}

We excluded pregnant women, children less than 18 years of age, patients with poly trauma, patients with significant metabolic diseases (CRF, CCF etc) and those patients who did not give consent.

\section{Clinical Information}

All patients had undergone a CT scan (brain plain). The routine lab tests were conducted for $\mathrm{CBC}$, coagulation profile, PT, APTT, renal and liver profiles (LFTs, RFTs) and other relevant tests for the stabilization for surgical intervention. 56 TBI patients were given standard treatment plus magnesium sulphate and remaining 56 patients received just standard treatment.

\section{Treatments of TBI}

The regular mode of treatment for TBI was that they received standard protocol treatment(patient is managed according to brain trauma guidelines, N.G/ Foleys passed, intravenous fluids, Mannitol infusion, antibiotics, nutrition, antiepileptic drugs as required, surgery if indicated) and along with this patients were given magnesium sulphate as an add on therapy. Blood samples for serum magnesium levels drawn on two occasions, at the time of admission and on the $3^{\text {rd }}$ day. Treatment guidelines consisted of an initial loading dose of $50 \mathrm{mg} / \mathrm{kg}$ magnesium sulfate and then 15 $\mathrm{mg} / \mathrm{kg}$ T.D.S up to 48 hours after the trauma. All the variables to be studied, including socio-demographic data like name, age, sex and address was collected. The clinical outcome was evaluated by using GOS (at 1 month).

\section{Data Analysis}

Data analysis was performed in SPSS (v.22.0, IBM Corporation) software. Categorical variables like gender were described as frequencies and percentages. Quantitative variables like age, weight, height, was described as mean +/- standard deviation. The continuous variable like serum Magnesium levels and age was presented in the form of mean and S.D. Qualitative variable like gender and grades of Glasgow Outcome Scale, was presented in the form of frequency and percentages. Data was stratified by age and gender with regard to outcome variable, i.e., Glasgow outcome score. A t test was used to compare the means of parameters between the groups. A $\mathrm{p}$ value $\leq 0.05$ was considered as significant.

\section{RESULTS}

There were 112 patients with primary brain trauma enrolled in the Neurosurgery Department of Shaikh Zayed Hospital, Lahore. Patients were split into two groups $(\mathrm{n}=56)$ Magnesium sulfate group and $(\mathrm{n}=56)$ placebo group.

\section{Age Incidence}

Mean age of the magnesium supplement therapy group was 36.8 years, while in the placebo group was 33.6 years (Table 1).

Table 1: Distribution of the Mean Age in the Study Groups.

\begin{tabular}{|l|l|c|c|}
\hline & Group of Treatment & Mean & $\begin{array}{c}\text { Std. } \\
\text { Deviation }\end{array}$ \\
\hline \multirow{2}{*}{$\begin{array}{l}\text { Age of } \\
\text { patients }\end{array}$} & $\begin{array}{l}\text { Magnesium Supplement } \\
\text { therapy }\end{array}$ & 36.83 & 13.45 \\
\cline { 2 - 4 } & Placebo therapy & 33.64 & 12.88 \\
\hline
\end{tabular}

\section{Gender Distribution}

Table 2 shows that the majority were male, 38 $(67.9 \%)$ in the magnesium sulfate group while 37 $(66.1 \%)$ were in the placebo group.

Table 2: Distribution of the Gender in the Study groups.

\begin{tabular}{|l|l|l|l|l|}
\hline & & \multicolumn{2}{|l|}{ Gender of Patients } & \multirow{2}{*}{ Total } \\
\cline { 3 - 5 } & Male & Female & \\
\hline \multirow{2}{*}{$\begin{array}{l}\text { Group of } \\
\text { treatment }\end{array}$} & $\begin{array}{l}\text { Magnesium } \\
\text { Supplement therapy }\end{array}$ & 38 & 18 & 56 \\
\cline { 3 - 5 } & Placebo therapy & $67.9 \%$ & $32.1 \%$ & $100.0 \%$ \\
\cline { 3 - 5 } & & $66.1 \%$ & $33.9 \%$ & $100.0 \%$ \\
\hline
\end{tabular}

Table 3: Distribution of the Duration of the traumatic brain injury in the study groups.

\begin{tabular}{|l|l|l|c|}
\hline & Group of Treatment & Mean & $\begin{array}{c}\text { Std. } \\
\text { Deviation }\end{array}$ \\
\hline $\begin{array}{l}\text { Duration of } \\
\text { trauma } \\
\text { (in hours) }\end{array}$ & $\begin{array}{l}\text { Magnesium } \\
\text { Supplement therapy }\end{array}$ & 4.98 & 2.32 \\
\cline { 2 - 4 } & Placebo therapy & 5.05 & 2.48 \\
\hline
\end{tabular}




\section{Duration Since Injury}

Table 3 shows mean duration passed between hospital presentation and traumatic brain injury was 4.98 hours in the magnesium sulfate group while it was 5.05 in the placebo group.

\section{Statistical Analysis}

After applying $\mathrm{t}$ test it was evaluated that mean Glasgow outcome score was $3.57 \pm$ 1.33 in the magnesium sulfate group while $2.78 \pm 1.23$ in the placebo group and this difference was statistically significant (Table 4).

\section{Stratification of Data}

Data was stratified for the impact of the age, gender and duration elapsed between trauma and presentation of patients and presented in tables 5-7.

Table 5 describes the stratification of the Glasgow outcome score in the treatment groups with respect to age. Glasgow outcome score in patient with age $<30$ years was $3.65 \pm 1.20$ in magnesium sulfate group vs. $2.65 \pm 1.19$ in the placebo group. GOS, in patients with age $>30$ years was $3.45 \pm$ 1.41 in magnesium sulfate group vs. $2.93 \pm$ 1.28 in the placebo group.

Table 6 shows the stratification of the Glasgow outcome score in the treatment groups with respect to gender. Glasgow outcome score in male patients was $3.48 \pm$ 1.30 in magnesium sulfate group vs. $2.73 \pm$ 1.28 in the placebo group. GOS in female patients was $3.73 \pm 1.14$ in magnesium sulfate group vs. $2.88 \pm 1.40$ in the placebo group.

Table 7 shows the stratification of the Glasgow Outcome score in the treatment groups with respect to duration of Disease. Glasgow outcome score in patient after $1-6$ months post TBI was $3.50 \pm 1.23$ in magnesium sulfate group vs. $2.60 \pm 1.26$ in the placebo group. GOS in patients $>6$ hours of TBI was $3.75 \pm 1.14$ in magnesium sulfate group vs. $2.88 \pm 1.40$ in the placebo group.

CT scans are shown in figures. Figure 1
Table 4: Comparison of Mean Glasgow Outcome Score in the Both Study groups.

\begin{tabular}{|l|l|c|c|c|}
\hline & Group of treatment & Mean & $\begin{array}{c}\text { Std. } \\
\text { Deviation }\end{array}$ & P-value \\
\hline \multirow{2}{*}{$\begin{array}{l}\text { Glasgow Outcome } \\
\text { Score }\end{array}$} & $\begin{array}{l}\text { Magnesium } \\
\text { Supplement therapy }\end{array}$ & 3.57 & 1.23 & \multirow{2}{*}{0.002} \\
\cline { 2 - 4 } & Placebo therapy & 2.78 & 1.33 & \\
\hline
\end{tabular}

Table 5: Stratification of the Glasgow Outcome score in the treatment groups with Respect to Age.

\begin{tabular}{|c|l|c|c|c|}
\hline \multirow{2}{*}{ Age } & \multirow{2}{*}{ Group of Treatment } & \multicolumn{2}{|c|}{$\begin{array}{c}\text { Glasgow Outcome } \\
\text { Score }\end{array}$} & \multirow{2}{*}{ P-value } \\
\cline { 3 - 4 } & & Mean & $\begin{array}{c}\text { Std. } \\
\text { Deviation }\end{array}$ & \\
\hline \multirow{2}{*}{$\begin{array}{c}18-30 \\
\text { years }\end{array}$} & Magnesium Supplement therapy & 3.65 & 1.20 & \multirow{2}{*}{0.002} \\
\cline { 2 - 4 }$>30$ & Placebo therapy & 2.65 & 1.19 & \\
\hline \multirow{2}{*}{\begin{tabular}{c} 
years \\
\cline { 2 - 4 }
\end{tabular}} & Magnesium Supplement therapy & 3.45 & 1.41 & \multirow{2}{*}{0.16} \\
\hline
\end{tabular}

Table 6: Stratification of the Glasgow Outcome score in the treatment groups with Respect to Gender.

\begin{tabular}{|l|l|l|l|l|}
\hline \multirow{2}{*}{ Gender } & \multirow{2}{*}{ Group of Treatment } & \multicolumn{2}{|c|}{$\begin{array}{c}\text { Glasgow Outcome } \\
\text { Score }\end{array}$} & \multirow{2}{*}{$\begin{array}{c}\text { P- } \\
\text { value }\end{array}$} \\
\cline { 3 - 4 } & & Mean & $\begin{array}{c}\text { Std. } \\
\text { Deviation }\end{array}$ & \\
\hline \multirow{2}{*}{ Male } & Magnesium Supplement therapy & 3.48 & 1.30 & \multirow{2}{*}{0.01} \\
\cline { 2 - 4 } & Placebo therapy & 2.73 & 1.28 & \\
\hline \multirow{2}{*}{ Female } & Magnesium Supplement therapy & 3.73 & 1.14 & \multirow{2}{*}{0.05} \\
\cline { 2 - 4 } & Placebo therapy & 2.88 & 1.40 & \\
\hline
\end{tabular}

Table 7: Stratification of the Glasgow Outcome score in the treatment groups with Respect to Duration of Disease.

\begin{tabular}{|l|l|l|l|l|}
\hline \multirow{2}{*}{$\begin{array}{l}\text { Duration } \\
\text { of Disease }\end{array}$} & \multirow{2}{*}{ Group of Treatment } & \multicolumn{2}{|c|}{$\begin{array}{c}\text { Glasgow Outcome } \\
\text { Score }\end{array}$} & \multirow{2}{*}{ P-value } \\
\cline { 3 - 5 } & & Mean & $\begin{array}{c}\text { Std. } \\
\text { Deviation }\end{array}$ & \\
\hline \multirow{2}{*}{$\begin{array}{l}\text { months } \\
\text { mon }\end{array}$} & Magnesium Supplement therapy & 3.50 & 1.23 & \multirow{2}{*}{0.002} \\
\cline { 2 - 5 } & Placebo therapy & 2.60 & 1.26 & \multirow{2}{*}{0.39} \\
\hline \multirow{2}{*}{6 hours } & Magnesium Supplement therapy & 3.75 & 1.17 & \\
\cline { 2 - 5 } & Placebo therapy & 3.22 & 1.48 & \\
\hline
\end{tabular}


shows various types of traumatic brain injuries (extradural hematoma, contusion, diffuse axonal injury, acute subdural hematoma, subarachnoid hemorrhage). Figure 2 represents a CT scan of right sided acute subdural hematoma with significant midline shift. Figure 3 shows a CT scan of diffuse axonal injury.

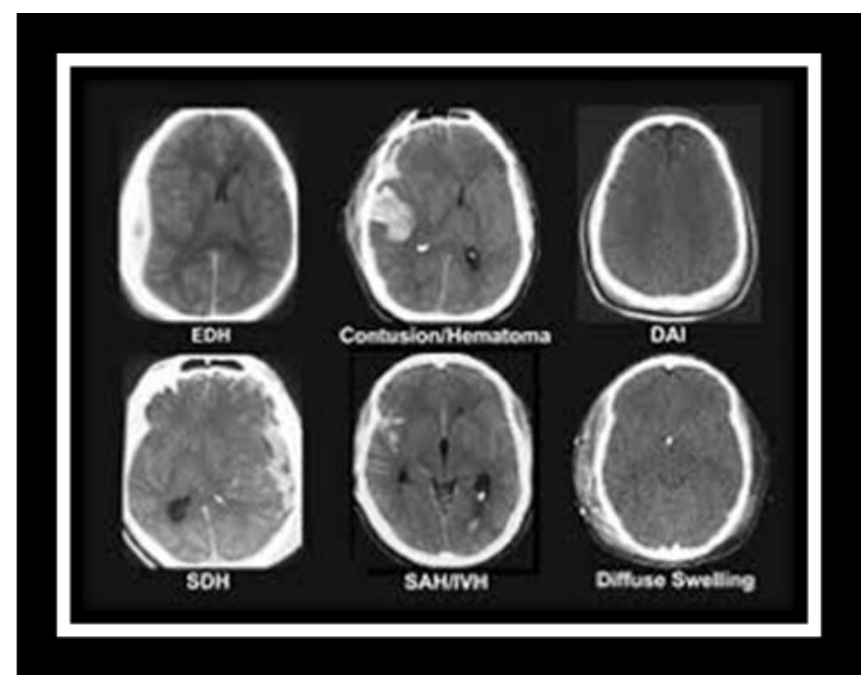

Fig. 1: CT scan showing various types of traumatic brain injury (extradural hematoma, contusion, diffuse axonal injury, acute subdural hematoma, and subarachnoid hemorrhage).

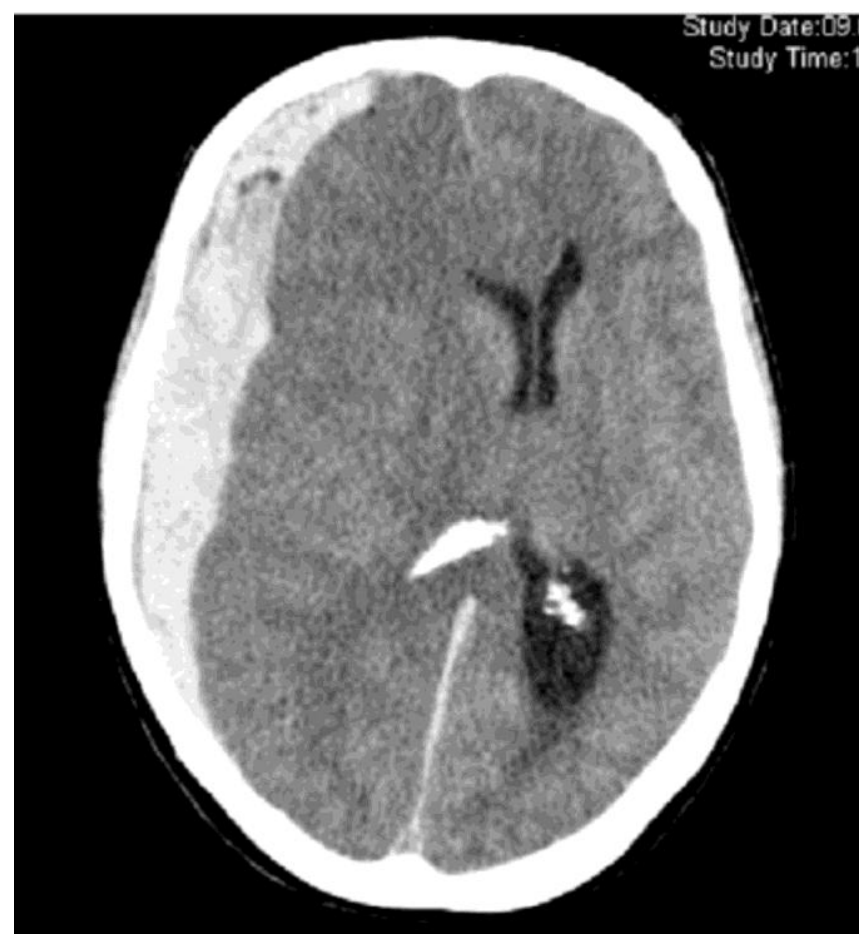

Fig. 2: CT scan of Acute Subdural Hematoma.

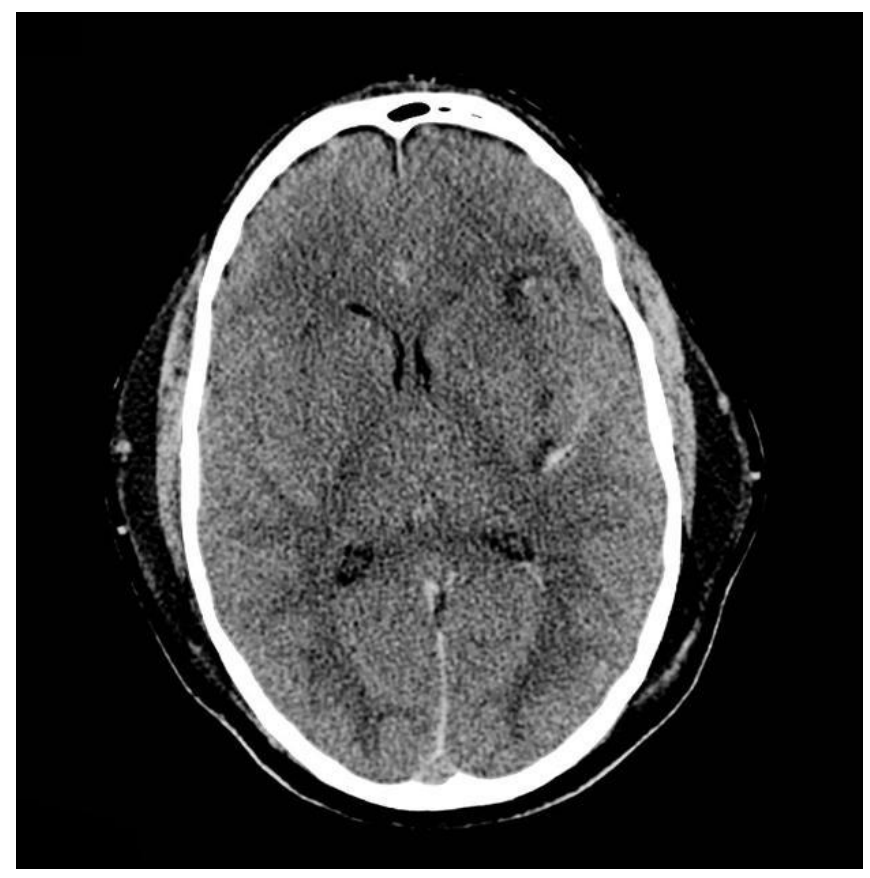

Fig. 3: CT scan of Diffuse Axonal Injury.

\section{DISCUSSION}

This study gives data on the efficacy of magnesium sulfate and its use in the patients with brain injury. More studies should be conducted to see the effects, efficacy, safety and increase in magnesium levels in the CSF with this therapy. Most studies have been done on the animals so insufficient data is available on human trials which means there is a need for more human clinical trials with magnesium therapy. One study (randomized controlled trial) gives the data regarding the effects of five-day intravenous infusion of magnesium sulfate therapy on the Glasgow coma scale and Glasgow outcome score and showed the comparison between the placebo and magnesium sulfate treatment groups in patients with brain trauma.

In a study done by Ling Zhao et al, (2016) there was significant improvement in GOS in MST (magnesium sulfate therapy) group as compared to placebo group. The mean GOS score was significantly higher in the MST group at discharge and 1 month after discharge consistent with the results of the current study. ${ }^{8}$

In spite of many clinical trials done on rodent animals which showed the efficacy of magnesium sulfate therapy and improvement in clinical outcome in patients with traumatic brain injury; in a recent study magnesium sulphate therapy didn't show any efficacy in improvement of clinical outcome. ${ }^{15}$ 
Magnesium plasma levels were corrected in all patients, those in magnesium treatment group received additional doses of magnesium at least double magnesium plasma levels as compared to placebo. McKee et al, (2005) mentioned that magnesium didn't show any improvement in the clinical outcome at double plasma levels rather had serious side effects in many patients as compared to placebo group. The dose response of magnesium as seen in the preclinical studies, brought into attention that in patients with TBI, intravenous magnesium can only slightly increase the CSF magnesium levels. ${ }^{16-17}$

It's critical to know that this slight increase in CSF magnesium levels will be sufficient to increase the cellular free magnesium concentration which is mandatory for its neuroprotective properties. ${ }^{17}$

Habgood et al, (2007) reported that magnesium sulfate levels in the CNS depend on the integrity of blood brain barrier. In studies done on rats, brain injury led to more disruption of blood brain barrier which resulted in excessive magnesium entry into the cells for 24 hours, this doesn't happen in human CNS after trauma. ${ }^{18-19-20}$

It is therefore expected that magnesium levels in the cells may not be as in the clinical trials, in this case the peripheral effects of magnesium may be more than the central and will affect the vitals of the patient including the blood pressure and cerebral blood flow.

It is necessary to have more clear knowledge about the entry of magnesium into the human central nervous system to have better results from the therapy.

Neuronal cell death after brain injury has multiple factors that are why combination therapy is recommended in many reports. Combination therapies target more than one factor, have gained attention over the period of time and have more efficacy. Different combination therapies have been studied until now in patients with brain trauma and ischemia like magnesium in combination with growth factors, glutamate antagonists, vitamin B, immunosuppressant, hypothermia, antioxidants. Studies have shown various results in preclinical trials, among them a combination of magnesium and hypothermia had better results. Further clinical studies are recommended to see the efficacy of combined magnesium and hypothermia therapy in patients with brain ischemia. ${ }^{21-22-23}$

According to the meta-analysis, mortality was almost same between the groups. In a study done by $\mathrm{Li}$ et al, $(2015)^{24}$ the Glasgow outcome score was higher in the magnesium sulphate treatment group as compared to the placebo group, but the significance was marginal; post treatment change in the Glasgow outcome score was significantly higher in the magnesium sulphate treatment group as compared to placebo. $^{24}$ Magnesium treatment group showed significant improvement in GCS after two months post trauma ( $\mathrm{p}=0.03$ ). Motor functioning scores of patients in the $\mathrm{MgSO} 4$ group were higher than those in the control group but this was not statistically significant $(p=0.51)$. The study shows that magnesium sulphate treatment has neuroprotective effects in the CNS in patients with severe diffuse axonal injury. ${ }^{25}$ The results of these studies were in consistent with the results of the current study.

In a study done by Lyons et al, (2018) there was no major improvement in the GOS in the treatment group as compared to the placebo, although, GCS showed a significant improvement in the treatment group which was contrary to this study. ${ }^{26}$ Maselet al, (2010) is suggested that the magnesium sulphate shows the tendency to significantly improve the Glasgow Outcome Scale and Glasgow Coma Scale score, this is very positive result for traumatic brain injury therapy. ${ }^{27}$

From the current research it's quite obvious that the use of magnesium sulphate therapy is beneficial for the patients with traumatic brain injury, it improves the Glasgow Outcome Scale and the Glasgow coma score which is consistent with other studies. More studies need to be done to come to a conclusion that in which type of brain trauma, the magnesium sulphate therapy would have the better outcome.

\section{CONCLUSION}

It was observed that the use of the Magnesium sulphate in the patients presenting with the traumatic brain injury must be emphasized and should be used as an add-on therapy along with the standard treatment protocols so that patients could be recovered from the injury. It is further recommended that more studies should be carried out on the trauma patients. Generalizability of the results of this study depends on the future studies.

\section{REFERENCES}

1. Mckee AC, Daniel H, Danesh VAR. The neuropathology of traumatic brain injury. Handb Clin Neurol. 2015; 127: 45-66.

2. Marehbian J, Muehlschlegel S, Edlow BL, Hinson HE, Hwang DY. Medical Management of the severe 
traumatic brain injury patient. Neurocrit Care, 2017; 26 (3): 12017-028.

3. Li M, Zhao Z, Yu G, Zhang J. Epidemiology of traumatic brain injury over the world: A Systematic Review .Gen Med (Los Angel), 2016; 4 (5): 271-284.

4. Salehpour F, Shakeri M, Ahmadvand A, Vafaee R, Jafari R, Safaiyan A. Magnesium Sulfate effect on the clinical course and GCS of patients with a severe diffuse axonal injury. JPS 2012; 3 (4): 70-75.

5. Kochanek PM, Jackson TC, Ferguson NM, Carlson SW, Simon DW, Brockman EC, et al. Emerging therapies in traumatic brain injury. J Semin Neurol. 2015; 35 (1): 83-100.

6. Busingye DS, Turner RJ, Vink R. Combined Magnesium/Polyethylene Glycol Facilitates the Neuroprotective effects of magnesium in traumatic brain injury at a reduced magnesium dose. CNS Neuroscience \& Therapeutics, 2016; 22: 854-859.

7. Vink R. Magnesium in the CNS: recent advances and developments. Magnesium Research, 2016; 29 (3): 95101.

8. Zhao L, Wang W, Zhong J, Li YY, Cheng YZ, Su Z, et al. The effects of magnesium sulfate therapy after severe diffuse axonal injury. Ther Clin Risk Manag. 2016; 12: 1481-1486.

9. Li W, Bai YA, Li YJ, Liu KG, Wang MD, Xu GZ, Shang HL, Li YF. Magnesium sulfate for acute traumatic brain injury. J Craniofac Surg. 2015; 26 (2): 393-8.

10. Can Magnesium Sulphate Prevent Cerebral Ischemic Injury? An Experimental Study and Neuroradiological Evidence. J Neurol Sci Turk. 2013; 30 (1): 030-039.

11. Sharp DJ, Beckmann CF, Greenwood R, Kinnunen KM, Bonnelle V, De Boissezon X, Powell JH, Counsell SJ, Patel MC, Leech R. Default mode network functional and structural connectivity after traumatic brain injury. Brain. 2011 Aug 1; 134 (8): 2233-47.

12. Faul M, Xu L, Wald MM, Coronado VG. Traumatic brain injury in the United States. emergency department visits, hospitalizations, and deaths, 2010: 2010.

13. Faul M, Xu L, Wald MM, Coronado VG. Traumatic brain injury in the United States. emergency department visits, hospitalizations, and deaths, 2010: 2010.

14. Frieden T, Collins F. Report to congress on traumatic brain injury in the United States: understanding the public health problem among current and former military personnel. NIH, DoD, VA Leadership Panel: CDC. 2013.

15. Temkin NR, Anderson GD, Winn HR Magnesium sulfate for neuroprotection after traumatic brain injury: a randomised controlled trial. Lancet Neurol. 2007; 6: 29-38.
16. Heath DL, Vink R. Optimization of magnesium therapy following severe diffuse axonal brain injury in rats. J Pharmacol Exp Ther. 1999; 288: 1311-6.

17. McKee JA, Brewer RP, Macy GE, Phillips-Bute B, Campbell KA, Borel CO. Analysis of the brain bioavailability of peripherally administered magnesium sulfate: A study in humans with acute brain injury undergoing prolonged induced hypermagnesemia. Crit Care Med. 2005; 33: 661-6.

18. Habgood MD, Bye N, Dziegielewska KM, Ek CJ, Lane MA, Potter A. Changes in blood-brain barrier permeability to large and small molecules following traumatic brain injury in mice. Eur J Neurosci. 2007; 25: 231-8.

19. Heath DL, Vink R. Delayed therapy with magnesium up to $24 \mathrm{~h}$ following traumatic brain injury improves motor outcome. J Neurosurg. 1999; 90: 504-9.

20. Miller JW, D. Ambrosio R. When basic research does not translate to the bedside lessons from the Magnesium Brain Trauma study. Epilepsy Curr. 2007; 7: 133-5.

21. Scholler K, Zausinger S, Baethmann A, Schmid Elsaesser R. Neuroprotection in ischemic strokecombination drug therapy and mild hypothermia in a rat model of permanent focal cerebral ischemia. Brain Res. 2004; 1023: 272-8.

22. Kwon BK, Roy J, Lee JH, Okon EB, Zhang H, Marx JC, Magnesium chloride in a polyethylene glycol for mulation as a neuroprotective therapy for acute spinal cord injury: preclinical refinement and optimization. $\mathrm{J}$ Neurotrauma, 2009; 24: 24.

23. Iotti S, Malucelli E. In vivo assessment of $\mathrm{Mg}$ in human brain and skeletal muscle b P-MRS. Magnes Res. 2008; 21: 157-62.

24. Li W, Bai YA, Li YJ, Liu KG, Wang MD, Xu GZ, Shang HL, Li YF. Magnesium sulfate for acute traumatic brain injury. Journal of Craniofacial Surgery, 2015 Mar. 1; 26 (2): 393-8.

25. Shakeri M, Salehpour F, Ahmadvand A, Jafari R, Safaiyan A, Meshkini A. Effects of magnesium sulfate on the clinical course and GCS of patients with a severe diffuse axonal injury. Journal of Injury and Violence Research, 2012 Nov; 4 (3 Suppl. 1).

26. Lyons MW, Blackshaw WJ. Does magnesium sulfate have a role in the management of severe traumatic brain injury in civilian and military populations? A systematic review and meta-analysis. Journal of the Royal Army Medical Corps. 2018 Apr. 17: JRAMC2018.

27. Masel BE, DeWitt DS. Traumatic brain injury: a disease process, not an event. Journal of Neurotrauma, 2010 Aug. 1; 27 (8): 1529-40. 


\section{Additional Information}

Disclosures: Authors report no conflict of interest.

Ethical Review Board Approval: The study was conformed to the ethical review board requirements.

Human subjects: Consent was obtained by all patients/participants in this study.

Conflicts of Interest:

In compliance with the ICMJE uniform disclosure form, all authors declare the following:

Financial Relationships: All authors have declared that they have no financial relationships at present or within the previous three years with any organizations that might have an interest in the submitted work.

Other Relationships: All authors have declared that there are no other relationships or activities that could appear to have influenced the submitted work.

Address for correspondence:

Kazim Ali

Punjab Institute of Neurosciences, Lahore

Email:doctorkazimali@hotmail.com

\section{AUTHORSHIP AND CONTRIBUTION DECLARATION}

\begin{tabular}{|l|l|l|}
\hline Sr.\# & Author's Full Name and Affiliation & Intellectual Contribution to Paper in Terms of: \\
\hline 1. & Muhammad Afaq Sarwar & Study design and methodology. \\
\hline 2. & Kazim Ali & $\begin{array}{l}\text { Paper writing, referencing, data calculations, Data collection, } \\
\text { analysis and interpretation }\end{array}$ \\
\hline 3. & Muhammad Irfan & Analysis of data and interpretation of results etc. \\
\hline 4. & Rabia Abbas & Literature review, manuscript writing and referencing \\
\hline 5. & Kamran Hussain & Analysis of data and quality insurer \\
\hline
\end{tabular}

Date of Submission: 18-4-2020

Date of Revision: 01-06-2020

Date of Online Publishing: 30-06-2020

Date of Print: 30-07-2020 